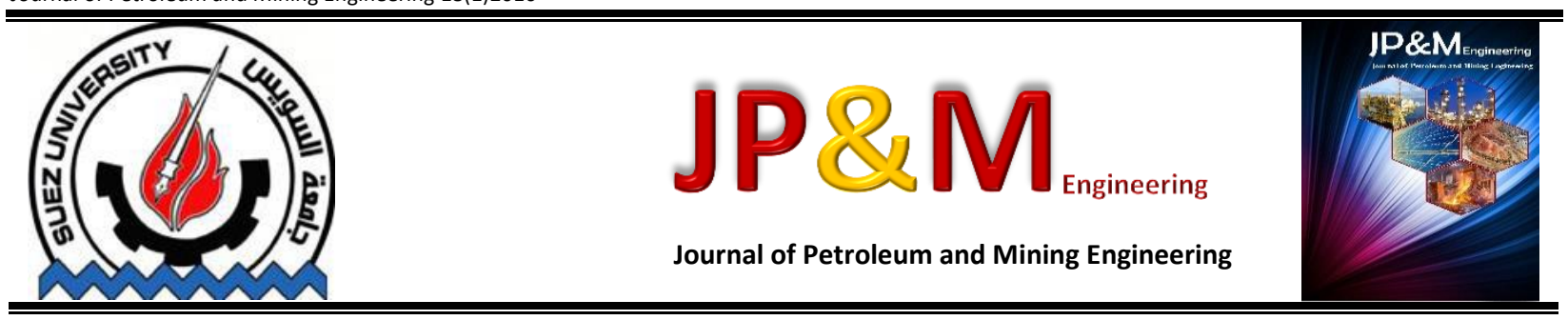

\title{
An Optimum Limited Entry for Multiple Zone Stimulationby Hydraulic Fracturing
}

\author{
A. A. Elgibaly ${ }^{a}$, M.S. Farhat ${ }^{a}$, M.A. Othman ${ }^{\text {b* }}$ \\ a Faculty of Petroleum and Mining Engineering, Suez University, Egypt \\ ${ }^{b}$ Qarun Company., Egypt. \\ *Corresponding author: Mosman@Qarun.net
}

\section{Keywords}

Limited Entry; Stimulation; Hydraulic Fracture; Fracture geometry; Perforation Friction.

\begin{abstract}
In hydraulic fracturing, various diversion methods have been used to treat multiple zones with greater or lesser degree of effectiveness. Limited entry fracturing "LEF" is one of them. LEF could be very effective and can result in considerable savings in well completion costs. The process is not difficult to apply. The technique of limited entry perforations is used to achieve large frictional pressure drop across certain perforations to ensure fluid injection through each perforation in each interval. This study presents a new development in LEF. New relations were developed to optimize the perforations number that could not only increase the bottomhole pressure, but also, could result in the optimum fracture geometry in each zone which leading to several increase in post-fracture productivity. The validation of these relations was checked by hydraulic fracturing simulator "Frac-CADE ${ }^{\mathrm{TM}}$ " utilizing data of a well which was treated before with hydraulic fracturing using an expensive isolation method. This study is the first-of-its-kind up to the author knowledge that considers the perforations erosion by proppant corrosive action in the design of this technique in order to prevent the perforation friction pressure loss and keep successful diversionof the fracturing fluid between different zones to the end of the treatment.
\end{abstract}

\section{Introduction}

Usually there are several potential producing zones penetrated by a wellbore that must be hydraulically fractured. To ensure that each zone is stimulated effectively, an isolation or diversion method has to be used.

The diversion technique of LEF is used to achieve a large frictional pressure drop across certain perforations (e.g., in a given layer) in an attempt to ensure fluid injection through each perforation in the completed interval ${ }^{1}$. The high pressure drop across the perforations is designed to be high enough to cause the bottomhole treating pressure in the casing to exceed the various fracturing pressures of the perforated zones ${ }^{2}$.
In Dec. 3, 1960, the first LEF treatment was performed in Shell TXL M-3, TXL Tubb Field, Ector country, Tex. Which had been perforated with four hole over the full interval resulted in production increase which averaged some 700 percent ${ }^{3}$. In this early time treatment, no post fracture evaluation method was applied.

From Dec. 3, 1960 to Jan. 1, 1963, Shell Oil Co. in Texas and New Mexico has treated 363 wells by this technique. The production performance of wells treated by LEF is superior by comparing to conventionally treated wells. The mechanism was described in Figure-1. Gamma ray tracer logs indicate most of the pay was treated even through not covered by perforations. Results of these simultaneous treatments have been gratifying in both well performance and reduced costs ${ }^{4}$. But, the radioactive traces were used to detect the height only of the fracture. 

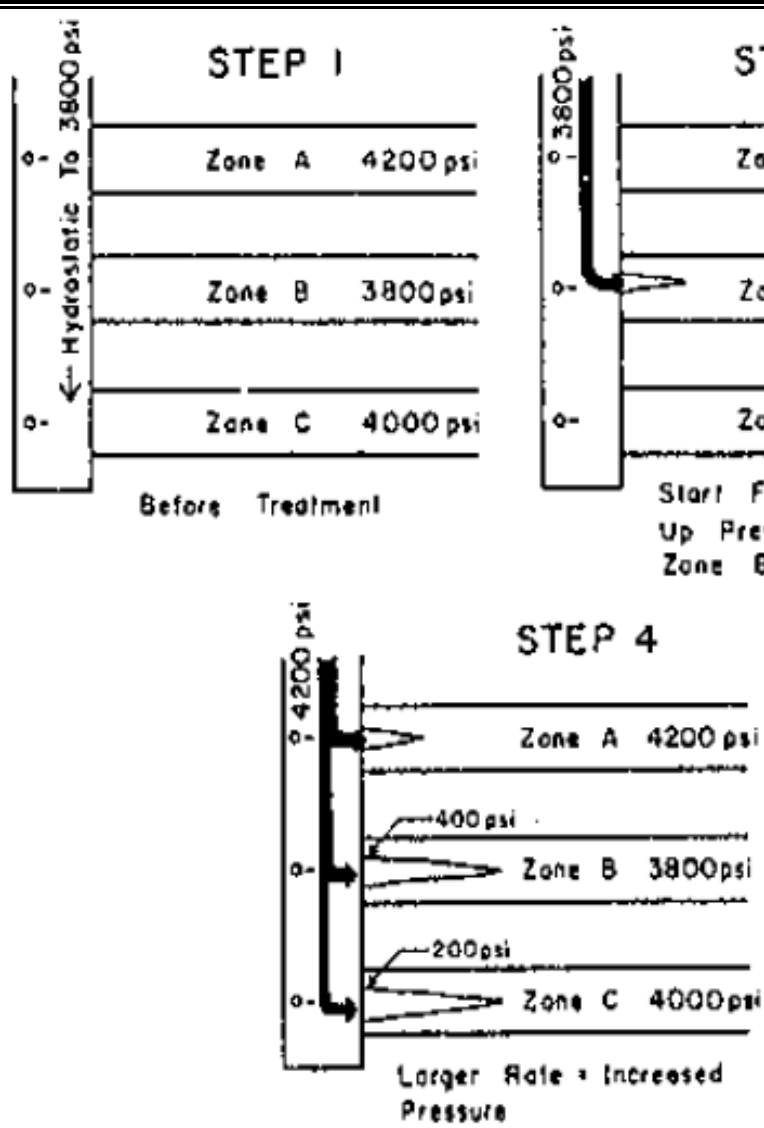
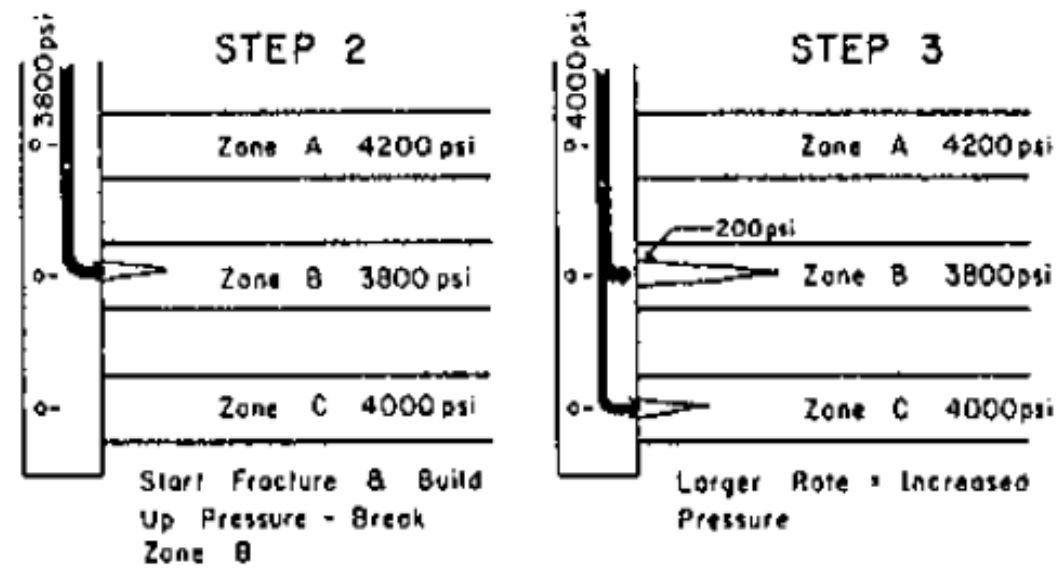

STEP 5

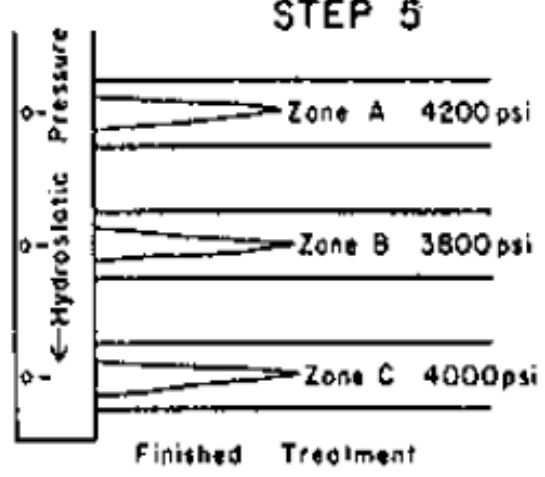

Figure 1 Limited entry fracturing "LEF' basic mechanism [Lagrone and Rasmussen-1963].

So, the whole geometry of each fracture wasn't considered.

Application of the limited technique has been also extended to massive hydraulic fracturing (MHF) of low permeability formations, such as the Niobrara and Codell intervals of DJ basin ${ }^{5-6}$.

LEF is considered feasible for treating the thin and lower permeability sandstone interbeded with shale in Daqing oil fields. From fifteen to twenty individual layers were treated without the need of manipulating the tubing string during one fracturing job with small volumes. Various types of postfracture tests revealed that $80-90 \%$ of the objective formations are stimulated ${ }^{7}$.Nevertheless, covering $80 \%$ percent of the layers is not accepted. The design of LEF was developed particularly for Daqing oil field based on determining the optimum injection rate from the past field experience in Daqing field ${ }^{8}$. However, no postfracture evaluation was considered to evaluate the diversion efficiency. The recent studies on LEF in Daqing field revealed it's not possible to group all the intervals in one huge treatment due to the extreme difference in fracturing pressure and the possible interference between the fractures ${ }^{9}$.

For Nioborara formation found in Adams Boulder and weld countries of Colorado, C.R. Eason mention that many different stimulation and diversion methods had been used to stimulate this multiple zone without any success. Only LEF was proved to be successful. The results were confirmed from radioactive traces ${ }^{10}$. But again, the whole geometry of each fracture was not considered.

The LEF was used successfully in LJ oil field in china ${ }^{11}$. Multiple coal and sandstone formations were treated simultaneously in Sanjuan basin, New Mexico by LEF ${ }^{12}$. For the last both cases, the design strategy was based on controlling the fracture height without regarding the whole fracture geometry and conductivity.

Hai Hoang developed a model to calculate the injection profile during the LEF based on the temperature profile using distributed temperature sensor[DTS] fiber optic cables ${ }^{13}$. However, by using DTS, LEF is losing the most benefit item, its economics.

The recent studies 14 reported uneven proppant distribution during LEF during physical modeling of LEF treatment.

All the previous studies didn't mentioned a complete design procedure for LEF. The number of perforations was usually depend only on a fixed amount of perforation friction or related only to each zone height.

Accurately placing proppant into multiple zones by using traditional design for LEF is extremely difficult.A 
general design procedure for LEF that covering all the intervals and regarding the fracture geometry and the postfracture productivity for each interval is necessary required.

\section{Well data}

Table-1 represents the data for a well consisting of three different zones. This well was already treated before with hydraulic fracturing for all the three intervals. The pine Island method (Sand Plug) was the actualisolation method in this well, in which each zone was treated

separately. Some of the data that will be used in constructing the model was extracted from the earlier actual -hydraulic fracturing treatments that were done before to approach the actual geometry.

Table 1 Well data.

\begin{tabular}{|c|c|c|c|}
\cline { 2 - 4 } \multicolumn{1}{c|}{} & Zone-1 & Zone-2 & Zone-3 \\
\hline Formation Depth & 8325 & 8550 & 8734 \\
\hline Pay thickness, ft & 15 & 17 & 30 \\
\hline Rock type & ShalySandstone & ShalySandstone & ShalySandstone \\
\hline Permeability, md & 1 & 1.3 & 5 \\
\hline Porosity, \% & 17 & 10 & 12 \\
\hline Fracture Gradient, psi/ft & 0.7 & 0.62 & 0.69 \\
\hline Closure Gradient, psi/ft & 0.68 & 0.55 & 35 \\
\hline Fluid Efficiency, \% & 66 & 22 & 5647 \\
\hline Minimum In-situ Stress, psi & 5643 & 4707 & $4 \times 10^{-6}$ \\
\hline Young's Modulus, psi & $4 \times 10^{-6}$ & $4 \times 10^{-6}$ & 0.25 \\
\hline Poisson's ratio, fraction & 0.25 & 0.25 & 1735 \\
\hline Reservoir pressure, psi & 2200 & 980 & 35 \\
\hline
\end{tabular}

\section{Model Construction}

\section{Numerical Simulator}

The simulator will be Frac-CADE ${ }^{\mathrm{TM}}$ under Qarun License. Frac-CADE ${ }^{\mathrm{TM}}$, the Fracturing Computer Aided Design and Evaluation software provides the tools, techniques and simulators required for hydraulic fracturing treatment design and evaluation.

\section{Model Selection}

P3D models provide a compromise and are most often used in the industry for the evaluation of hydraulic fracturing treatments. This model will be the choice from Frac-CADE ${ }^{\mathrm{TM}}$ softwarefor all scenarios.

\section{Fracturing Fluid Selection}

Experience in the area dominates the selection of fracturing fluid. From Frac-CADE ${ }^{\mathrm{TM}}$ software data base, $\mathrm{X}$ Linked polymer with Schlumberger codeYF-140 will be used as the main fracturing fluid.

\section{Proppant Selection}

The volume and cost required to obtain an optimum or desired conductivity will be considered. 16/30 proppantmesh size will be used as an initial condition in the simulator, and then the conductivity result of the built model will be evaluated.

\section{Work Strategy}

Estimating the Optimum Perforations Number for LEF.

Equation-1 is the flow throw edge orifice equation 15. This is the most used equation in estimating the total perforations number " $n_{t}$ ".

$n_{t}=\sqrt{\frac{0.2369 \rho q^{2}}{\Delta P_{\text {Perf }} C_{d}^{2} D_{p}{ }^{4}}}$

Where;

$\Delta P_{\text {Perf }}=$ Perforations friction pressure, psi.

$q=$ Total flow rate, $\mathrm{bbl} / \mathrm{min}$.

$\rho=$ Fracturing fluid density, ppg.

$\mathrm{D}_{\mathrm{p}}=$ Perforation diameter, in . 
$\mathrm{C}_{\mathrm{d}}$ =Discharge coefficient represents the effect of the perforation entrance shape on the friction pressure.

The perforation friction pressure is representing the pressure required to offset the fracture pressure difference between the intervals.And so, it can be estimated from Equation-2.

$\Delta P_{\text {Perf }} \geq P_{f \text { max }}-P_{f \text { min }}$

Where;

$\mathrm{P}_{\mathrm{f} \max }=$ Maximum fracturing pressure, $\mathrm{psi}$.

$P_{f \min }=$ Minimum fracturing pressure, $p s i$.

The discharge coefficient can be calculated from ElRabaa correlation ${ }^{16}$ in Equation-3 and Equation-4

$C_{d}=\left[1-e^{\frac{-2.2 d}{\mu_{a}^{0.1}}}\right]^{0.4}$

$\mu_{a}=47880 K \gamma^{n-1}$

Where;

$\mu_{\mathrm{a}}=$ Apparent viscosity, $\mathrm{cp}$.

$\mathrm{K}=$ Power law fluid rheology consistency coefficient, $\mathrm{lbf}-\mathrm{s}^{\mathrm{n}} / \mathrm{ft}^{2}$.

$\mathrm{n}=\quad$ Power law fluid rheology behavior index, dimensionless.

$\gamma=$ Shear rate, $1 / \mathrm{s}$.

The perforations number required for each interval " $n_{i}$ " can be estimated from Equation- 5

$$
\frac{n_{i}}{n_{t}}=\frac{\left[\frac{0.2369 \rho q_{i}^{2}}{\Delta P_{i} C_{d}^{2} D^{4}}\right]_{i}^{0.5}}{\sum_{i=1}^{j}\left[\frac{0.2369 \rho q_{i}^{2}}{\Delta P_{i} C_{d}^{2} D p^{4}}\right]_{i}^{0.5}}
$$

Assuming the same perforations friction pressure for all the intervals, Equation-5 will have the following form in Equation-6

$\frac{n_{i}}{n_{t}}=\frac{q_{i}}{q_{t}}$

Where $\frac{q_{i}}{q_{t}}$ can be estimated from Elbel (1993) injection

profile17 in Equation-7

$\frac{q_{i}}{q_{t}}=\frac{\left(P_{f}-\sigma_{\min }\right)_{i}^{\left(2 n^{\prime}+3\right)\left(n^{\prime}+1\right)}\left[h_{f}^{3} / E^{\prime 2} \mu^{1 /\left(n^{\prime}+1\right)}\right]_{i}}{\sum_{i=1}^{j}\left(P_{f}-\sigma_{\min }\right)_{i}^{\left(2 n^{\prime}+3\right)\left(n^{\prime}+1\right)}\left[h_{f}^{3} / E^{\prime 2} \mu^{1 /\left(n^{\prime}+1\right)}\right]_{i}}$

Where,

$\mathrm{h}_{\mathrm{f}}=$ Fracture height, $\mathrm{ft}$.

$\sigma_{\min }=$ Minimum in-situ stress, psi.

$\mathrm{E}^{\prime}=$ Plane strain modulus, psi.

$\eta=$ Fluid efficiency, fraction.

$\mathrm{n}^{\prime}=$ Power law effective index,

dimensionless.

Each zone in Equation-7 was assumed by Elbel to be confined or had a moderate height growth ${ }^{17}$. However, the excess in the fracture height growth can lead to undesirable interference between fractures ${ }^{9}$. By inserting the desired net pressure $\left(\mathrm{P}_{\mathrm{f}}-\sigma_{\min }\right)$ in the Equation-7 that can create the required geometry, the resulted flow rate ratio for each interval will be optimized and so the perforations number

The important issue that has to be regarded, the minimum number of perforations must be at least two shots or greater. The phasing for each zone must be $180^{\circ}$ phasing or less for the perforation alignment ${ }^{18}$.

\section{Modeling The Data Through three Scenarios}

The validation of perforation calculation procedure will be evaluated from the results of the generated model for the following scenarios:

Scenario-1: The model will be generated for uniform perforation pattern, in anothermeaning, without any diversion.

Scenario-2: The second run will be with the calculated perforation number in the previous procedure to attain the diversion. The same net pressure achieved for each zone in the previous actual stimulation utilizing pine island field method will be used in calculating the optimum perforation number.

Scenario-3: The decline of the perforation friction due to the erosion effect of the proppant on the perforations will be considered on this scenario.

\section{Results \& Discussion}

Many runs have been made on Frac-CADE ${ }^{\mathrm{TM}}$ to construct the models for the last mentioned procedures and the following results were obtained.

\section{The First Scenario: Generating the Model without Using} Diversion

This scenario was achieved by running the simulator with the normal perforations profile in the industry. This normal perforation profile was fulfilled utilizing six shot per foot.The resulted perforations profile is mentioned in Table-2.As it can be expected, the treatment was completely failed and premature screen-out was occurred.

Table 2 Perforation profiles for the three scenarios.

\begin{tabular}{|c|c|c|c|}
\cline { 2 - 4 } \multicolumn{1}{c|}{} & \multicolumn{3}{c|}{ Perforations Profile, shots number } \\
\cline { 2 - 4 } \multicolumn{1}{c|}{} & Scenario-1 & Scenario-2 & Scenario-3 \\
\hline Zone-1 & 90 & 2 & 2 \\
\hline Zone-2 & 102 & 6 & 3 \\
\hline Zone-3 & 180 & 8 & 4 \\
\hline
\end{tabular}

The Second Scenario: Generating the Model for the Calculated Perforation Profile in 4.1 
The perforations profile for the second scenario in Table 2 was used in constructing the model for this scenario. The execution of the treatment by the simulator demonstrates the completion of the treatment to the end. Fracture length and dimensionless fracture conductivity are the most important parameters that control the post fracture productivity. Figure-2and Figure-

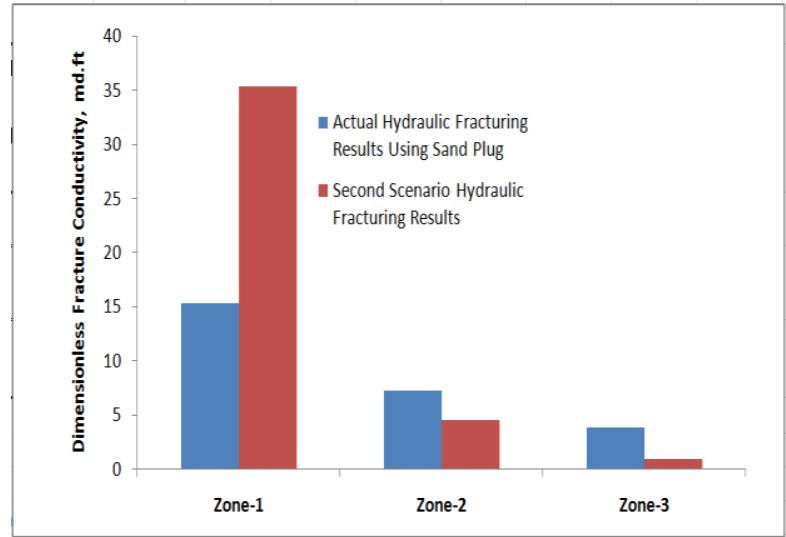

Figure 2 Comparison between the actual and the second scenario dimensionless fracture conductivity.
3 comparing the fracture dimensionless conductivity " $\mathrm{CfD}_{\mathrm{fD}}$ and the fracture half length " $X_{f}$ " resulted from the built model in the second scenario to the actual hydraulic fracturing treatments. However, there's still a gap between the desired and the simulated fracture geometry and conductivity for some reason.

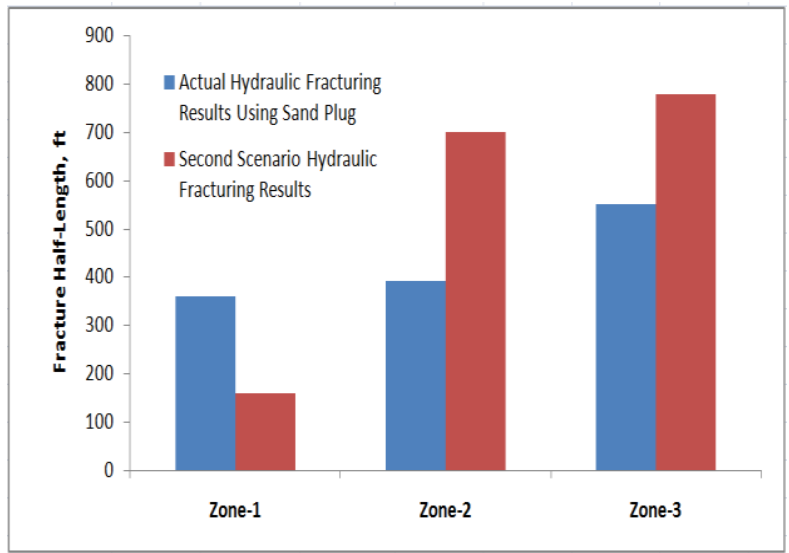

Figure 3 Comparison between the actual and the second scenario fracture half length. 

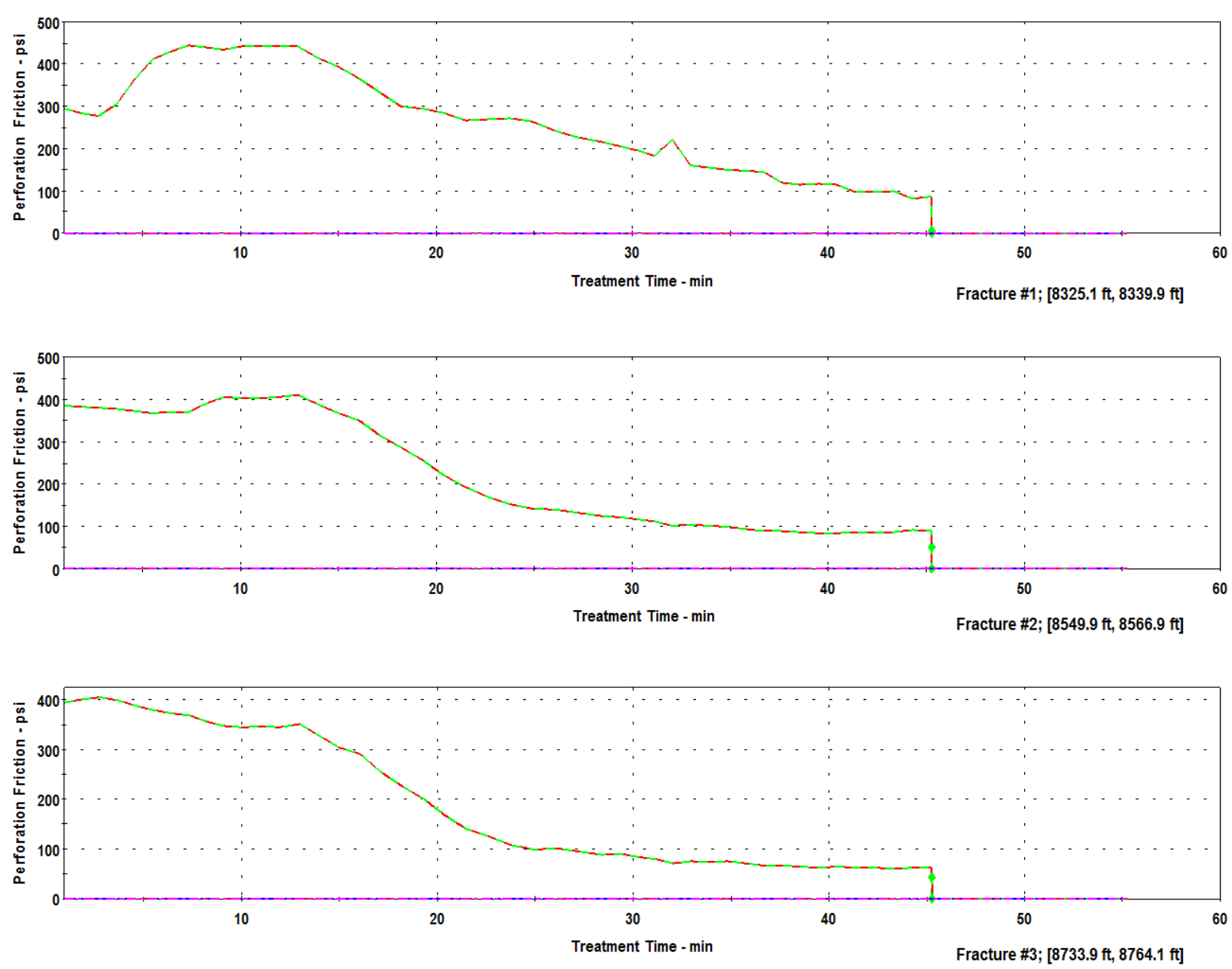

Figure 4 Perforation friction Vs. Treating Time in the second scenario- Frac-CADE ${ }^{\mathrm{TM}}$.

Figure 4show the perforation friction predicted by the simulator during the treatment. From the rate of increase of pressure, it's obvious that the second and the third zones start to accept fluid causing the fracture pressure to increase. This increase in pressure causes the fluid to be diverted to the first zone. Also, it can be noticed that, the most of perforation friction essential for the diversion is lost nearby the ending of the treatment. The abrasive action of the proppant on the perforation during the treatment is suspicious of this drop of pressure.

For giving exact approach for this problem; the perforation friction wasinvestigated from twodownhole memory gauges extracted from two dead stringswhich were used before in actual LEF

treatments. Assuming zero tortuosity, the perforation friction was determined by subtractinginstantaneous shut-in pressure "ISIP" from bottomhole treating pressure as in Figure 5 and Figure 6. 


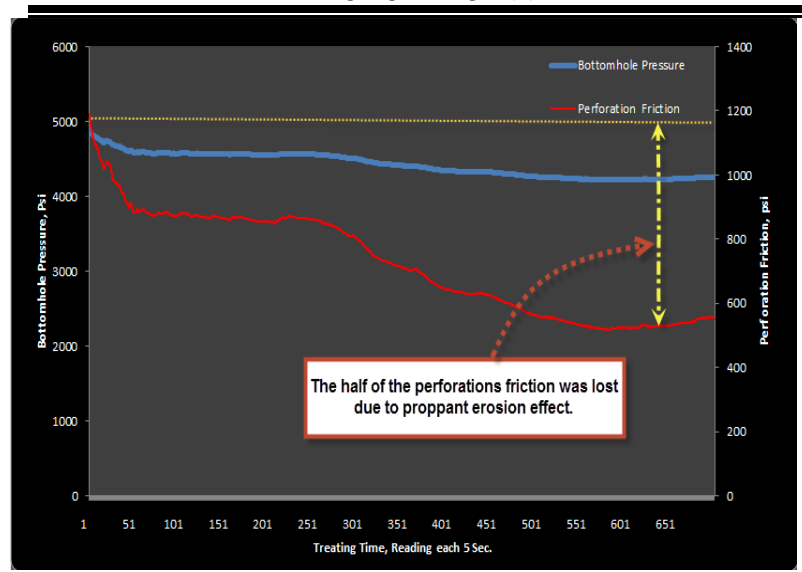

Figure 5 Perforation pressure drop during actual limited entry hydraulic fracturing treatment- Case-1.

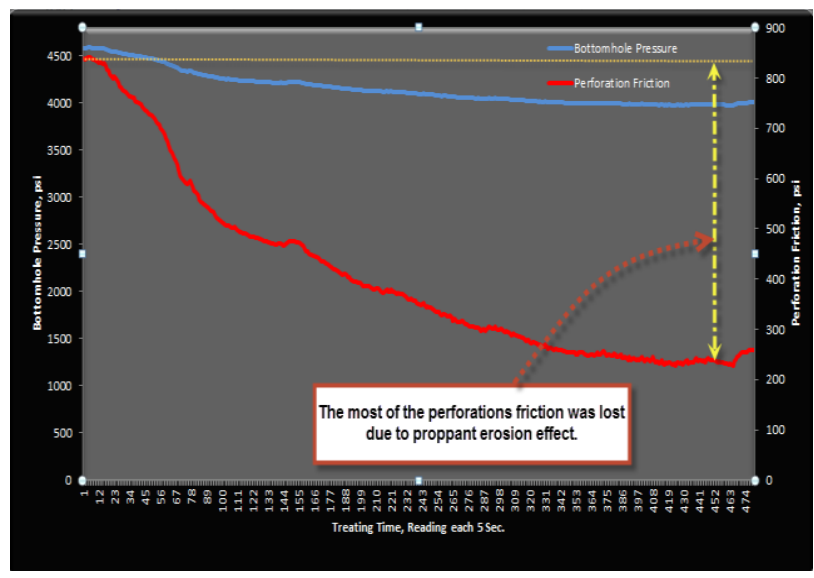

Figure 6 Perforation pressure drop during actual limited entry hydraulic fracturing treatment, Case-2.

From the first case in Figure 5, more than the half of the perforation friction was lost. From the second case in Figure 6, approximately the total of the perforation friction was lost. So, it can be concluded that, there's extreme drop in perforation friction during the treatment due to the abrasive action of proppant. The diversion is not only can be affected but it may be completely lost. It's call now for a remedy.
The Third Scenario: Generating the Model with Modifying Perforation Profile in 4.1

The target now is to modify the perforations profile in the way that reserving at least the minimum perforation pressure required for diversion during the whole treatment. In the other hand, this modified perorations profile has to keep the same perforations number ratio for each zone. This will be attained by using a percent of the total perforationsnumber. Following a trial and error method till reach the optimum geometry. By using the half of the total perforation number in the second scenario regarding that the minimum number of perforations will be two shots to have at least $180^{\circ}$ phasing as discussed before.

From Figure 7, the perforation friction for the three zones remained at the end of the treatment is $726 \mathrm{psi}$. This value of perforation friction is approximately close to the minimum value required to manage diversion.

In Figure 8 and Figure 9, CfD and Xf that were resulted from the third scenario had close values to the actual values resulted from the actual expensive isolation method.

Following unified fracture design method "UFD" 19, post-treatment skin for each interval is estimated and listed in Table-3. This negative skin values for all the intervals are leading to several folds-of-increase in well performance compared to the unstimulated well as in the same table. The value of the skin factor and the fold-ofincrease in productivity index for each zone for this scenario are approximately close which could indicate the uniform distribution of the fracturing fluid in all the zones.

Table 3 Skin factor and fold-of-increase in PI for the three zones for the third scenario.

\begin{tabular}{|c|c|c|}
\cline { 2 - 3 } \multicolumn{1}{c|}{} & Skin Factor "S" & $\begin{array}{c}\text { Fold-Of-Increase } \\
\text { in PI "FOI" }\end{array}$ \\
\hline Zone-1 & -6.67 & 3.53 \\
\hline Zone-2 & -7.2 & 4.81 \\
\hline Zone-3 & -6.73 & 3.42 \\
\hline
\end{tabular}




\section{Near Wellbore Pressure History}
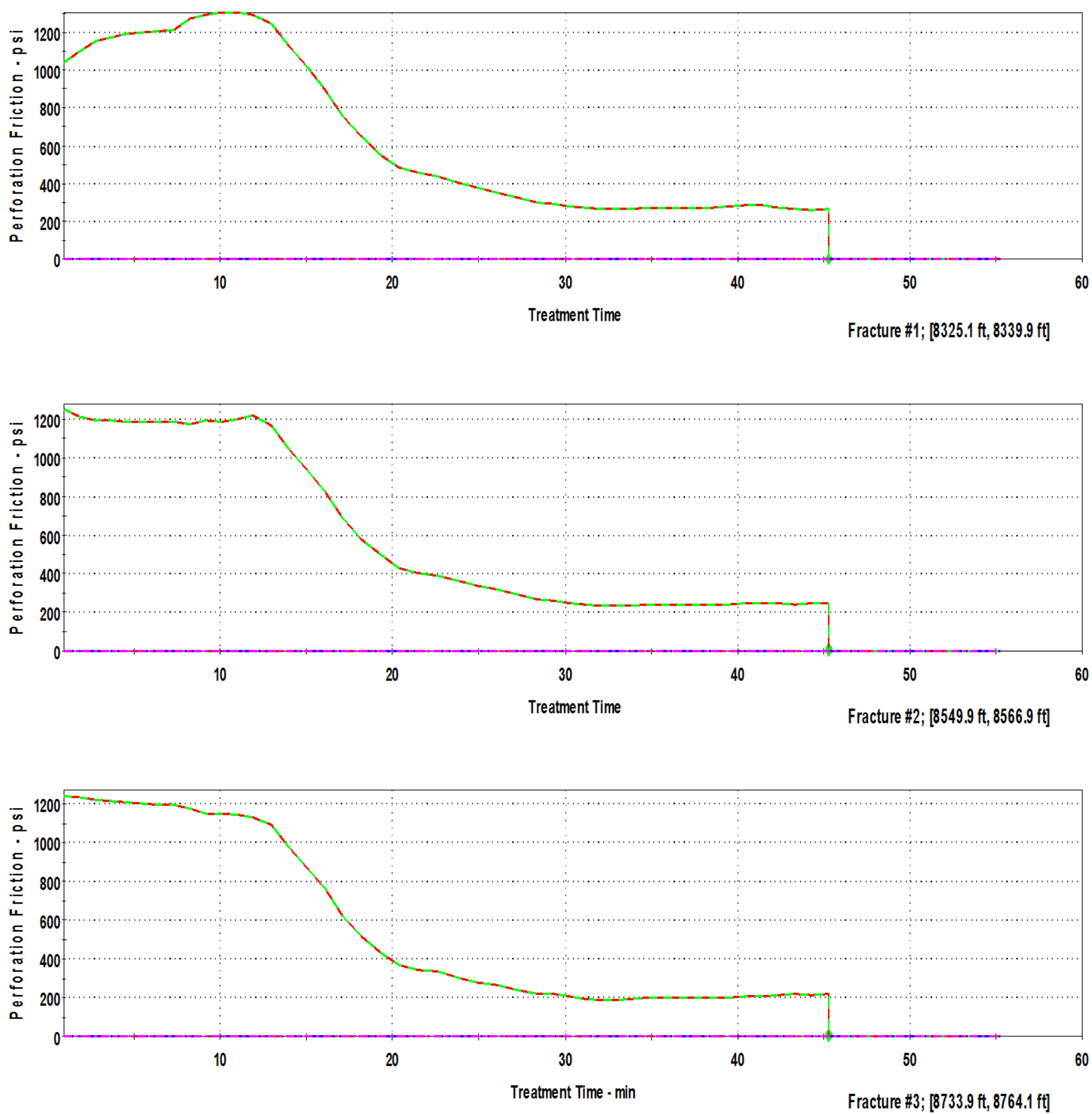

Figure 7 Perforation friction Vs. Treating Time in the third sc enario- Frac-CADE ${ }^{\mathrm{TM}}$. 


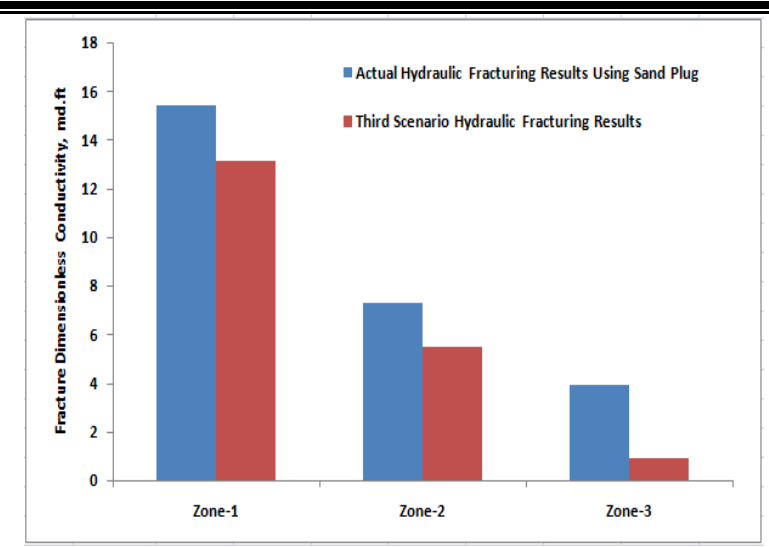

Figure 8 Comparison between the actual and the third scenario fracture dimensionless conductivity.

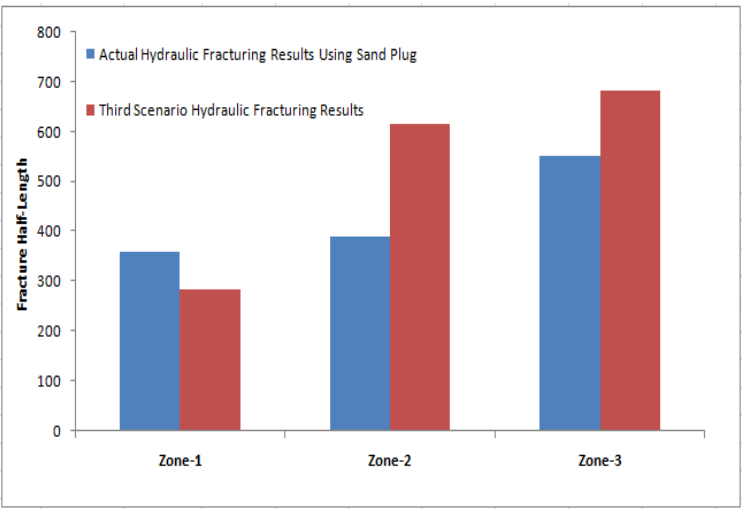

Figure 9 Comparison between the actual and the third scenario fracture half length.

\section{Conclusion}

The main conclusions drawn from this research are listed below:

New reliable perforation profile calculation procedure has been developed for limited entry technique, this will aid in diversion optimization.

The simulation provided an engineering tool that help in determining the resulted fractures geometries, by which the diversion was evaluated.

The proppant erosion effect on the perforations was found destructive for the perforation friction pressure and could result in a complete loss of the diversion.

By using the third scenario; the erosion of the perforation can't be prevented but the remained perforation friction at the end of the treatment is enough for attaining a successful diversion.

\section{References}

[1] Elbel, J.L. and Larry, B.: "Fracture Treatment Design," Chapter 10 in M.J. Economedes and K.G. NolteReservoir Stimulation Third Edition, Wiley, New York, U.S.A. (2000).
[2] Schlumberger Company: Diverting Techniques-Internal Paper.

[3] Murphy, W.B. and Juch, A.H.: " Pin point Sand Fracturing-A Method of simultaneous injection into Sand," Paper SPE 1415,Journal of Petroleum Technology (Nov. 1960).

[4] Lagrone, K.W. and Rasmussen, J.W.: "A New Development in Completion Methods -The Limited Entry Technique," paper SPE 530, Journal of Petroleum Technology (July 1963).

[5] Cramer, D.D.: "The Application of Limited Entry Techniques in Massive Hydraulic Treatments," Paper SPE 16189, Presented at the SPE Production Operations Symposium Held in Oklahoma, USA (8-10 March 1987).

[6] Eberhard M.J. and Schlosser, D.E.: "Current Use of Limited Entry Hydraulic Fracturing in the Codell/Niobrara Formation DJ Basin," Paper SPE 29553, presented the SPE Rocky Mountain Regional/Low Permeability Reservoir Symposium, Denever, Colorado, USA (20-22 March 1995).

[7] Zhou, Wang, Qi, Wenhui, Xiao, Pan, and Xie: "Devlopment in the Limited Entry Completion Fracturing Technique," Paper SPE 17834, Presented at the SPE International Meeting on Petroleum Engineering,Tianjin, China ( 1-4 Nov 1988).

[8] Demin, W., He, L., Wang, W. and Gang, W.: "How to Fracture More Than 30 Zones in a Well in One Day and Used in Large Scale," paper SPE84912, presented the SPE Improved Oil Recovery Conference, Kuala Lampur, Malaysia (20-21 October 2003).

[9] He, L., Zongguo, W, Qingping, W., Hongtian, Y., Jifeng, H., Zhixing, W. , Shifeng, Z., Jiachen, Z. and Zhiya, L. :"Study and Application of the Technology of subdivision controlled limited entry fracturing in Reservoir with Many Thin Layers," paper SPE 115371, presented at Oil \& Gas Exhibtion, Perth, Australia (20-22 October 2008).

[10] Harrison, N.W.: "Diverting Agents-History and Application," paper SPE 3653, Journal of Petroleum Technology (May 1972).

[11] Li, Y., Guo, J., XU, W. and Zhao, J. :"Pilot Test of Limited Entry Frac Applictions on Extra-Thick-Pay and Vertical Fracture Wells in the Massive Oil Pool," paper SPE 73787, presented at the SPE Formation Damage Control Sympsium and Exhibtion, Lafayette, Louisiana (20-21 February 2002).

[12] Bazan, L.W. and Lakrin, S.D. :"Limited Entry Techniques Prove Successful in Stimulaneously stimulating the Fruitland Coal and Pictured Cliffs Frormation in the San Juan Basin," paper SPE 74353, presented at the SPE International Petroleum Conference and Exhibtion, Villahermosa, Mexico (10-12 February 2002).

[13] Hoang, H., Mahdevan, J. and Lopez, H. :"Interpretation of Wellbore Temperature Measured Using Distributed Temperature Sensors During Hydraulic Fracturing," paper SPE 140442, presented at the SPE Hydraulic Fracturing Technology Conference and Exhibtion, Woodlands, Texas, USA (24-26 January 2011). 
[14] Crespo, F., Aven, N.K., Cortez, J., Soliman, M.Y., Bokane, A., Jain, S. and Deshpande, Y. :" Proppant Distribution in Multistage Hydraulic fractured Wells: A Largae Scale Inside Casing Investigation," paper SPE 163856, presented at the SPE Hydraulic Fracturing Technology Conference and Exhibtion, Woodlands, Texas, USA (4-6 February 2013).

[15] Mark G. Mack and Norman R. Warpinski: “Mechanics ofHydraulic Fracturing," Chapter 6 in M.J. Economedes and K.G. NolteReservoir Stimulation Third Edition, Wiley,New York, U.S.A.(2000).

[16] El-Rabaa, A.M.: "New Perforation Loss Correlations for Limited Entry Fracturing Treatments," Paper SPE Roccky Mountain Regional Meeting, Casper, Wyoming, U.S.A. (1821 May 1997).
[17] Elbel, J.L.: “A Method To Estimate Multizone Injection Profiles During Hydraulic Fracturing," paper SPE 21869, presented at the Rocky Mountain Regional Meeting and Low-Permeability Reservoirs Symposium, Denver, Colorado, U.S.A. (15-17 April 1993).

[18] Jennings, J.R., Westerman, D.W., Talock C.W., Westerman, R., and Anderson M.: "A Systematic Approach to Improved Success With Hydraulic Fracturing Applications" Paper SPE101387 presented at the SE Annual Technical Conference and Exhibition, San Antonio, Texas, USA (24-27 Sep. 2006).

[19] Economides, M., Oligney, R. and Valko, P.: Unified Fracture Design, Orsa, Alvin, Texas, USA (2002). 